\title{
PEMANFAATAN JASA LINGKUNGAN DI HUTAN DESA BUNTOI, KECAMATAN KAHAYAN HILIR, KABUPATEN PULANG PISAU, PROVINSI KALIMANTAN TENGAH
}

(The Utilisation of Environmental Service at Buntoi Village Forest, Kahayan Hilir District, Pulang Pisau Regency, Central Kalimantan Province)

Muhammad Zahrul Muttaqin ${ }^{1}$, Ismayadi Samsoedin ${ }^{2}$, Subarudi $^{1}$, Nurtjahjawilasa ${ }^{3}$, dan Faridh Almuhayat Uhib Hamdani $^{4}$

${ }^{1}$ Pusat Penelitian dan Pengembangan Sosial, Ekonomi, Kebijakan dan Perubahan Iklim, Badan Litbang dan Inovasi, Kementerian Lingkungan Hidup dan Kehutanan, Jl.Gunung Batu No.5, Bogor 16118, Jawa Barat, Indonesia.

E-mail: zahrul2005@yahoo.com.au,rudi.subarudi@yahoo.co.id

${ }^{2}$ Pusat Penelitian dan Pengembangan Hutan, Badan Litbang dan Inovasi, Kementerian Lingkungan Hidup dan Kehutanan, Jl.Gunung Batu No.5, Bogor 16118, JawaBarat, Indonesia.

E-mail: isamsoedin@yahoo.com

${ }^{3}$ Pusat Pendidikan dan Pelatihan, Kementerian Lingkungan Hidup dan Kehutanan, Jl. Gunung Batu No.141, Bogor 16118, Jawa Barat, Indonesia

E-mail: nurcahyowiloso@gmail.com

${ }^{4}$ Direktur Eksekutif MAP Institute, Vila Bogor Indah Blok DD2 No. 31, Ciparigi, Bogor 16157, Jawa Barat, Indonesia

E-mail: faridhalmuhayatuhib@yahoo.co.id

Diterima 6 Desember 2016, direvisi 22 Maret 2016, disetujui 31 Maret 2017

\begin{abstract}
Village forest is a managed state forest by village institution for the prosperity of villagers. Village that has granted village forest is responsible for its utilization and its sustainability. The development of village forest in Buntoi Village is still at the preliminary stage; therefore the identification of environmental services, policy, institutional arrangements, and sustainable potential livelihood need to be conducted. The purpose of this study is to identify and analyse the potential of ecosystem services and influencing factors in the utilization of the ecosystem services. The result showed that there was lack of water services in the Buntoi village since there was no spring water in the forest. Also did not have the beauty of potential landscape that can attract tourists. Moreover, the potential of biodiversity and carbon sequestration in the village had not been optimised. Low utilization of ecosystem services in Buntoi was due to: (1) perceptions of stakeholders that had not yet support the utilization of ecosystem services; and (2) lack of support from district and provincial in the utilization of ecosystem services in village forest. Activities that can be developed to utilize biodiversity, beauty of landscape, and carbon conservation in Buntoi are ecotourism and REDD+ scheme.
\end{abstract}

Keyword: Village Forest; Buntoi village; potential and use of environmental services.

\begin{abstract}
ABSTRAK
Hutan Desa (HD) merupakan hutan negara yang tidak dibebani hak dan dikelola oleh desa untuk kesejahteraan desa. Desa yang memiliki HD bertanggung jawab atas pemanfaatan sumber daya hutan secara lestari. Pengembangan HD di desa Buntoi masih dalam tahap awal sehingga perlu dilakukan penggalian potensi dari berbagai aspek seperti aspek jasa lingkungan, kebijakan dan kelembagaan, dan potensi mata pencaharian yang berkelanjutan. Tujuan penelitian ini adalah untuk mengidentifikasi dan menganalisis potensi jasa lingkungan beserta faktor-faktor yang memengaruhi dalam pengembangannya. Hasil penelitian menunjukkan bahwa pemanfaatan jasa air di Desa Buntoi selama ini hanya mengandalkan air sungai yang berwarna coklat karena tidak memiliki sumber mata air. Secara
\end{abstract}


bentang alam tidak ditemukan areal yang khas untuk dapat menarik kedatangan wisatawan, akan tetapi potensi keanekaragaman hayati dan penyerapan karbon di HD kurang optimal dimanfaatkan untuk menarik wisatawan. Ketidakoptimalan pemanfaatan jasa lingkungan di HD Buntoi disebabkan oleh: (1) Persepsi masyarakat lokal yang belum mendukung pemanfataan jasa ekosistem; dan (2) Kurangnya dukungan dari pemerintah daerah dalam pemanfaatan jasa ekosistem di hutan desa. Adapun kegiatan yang dapat dikembangkan untuk memanfaatkan keanekaragaman hayati, keindahan bentang alam, dan konservasi karbon di desa hutan yaitu ekowisata dan program pengurangan emisi berbasis REDD+.

Kata kunci: Hutan desa; Desa Buntoi; potensi dan pemanfaatan jasa lingkungan.

\section{PENDAHULUAN}

\section{A. LATAR BELAKANG}

Hutan desa (HD) didefinisikan sebagai hutan negara yang tidak dibebani hak yang dikelola oleh desa untuk kesejahteraan masyarakat desa (Kementerian Kehutanan, 2014). Pengaturan kelembagaan pengelola HD sedikit berbeda dibandingkan dengan pengelolaan kawasan hutan berbasis masyarakat lainnya, seperti hutan kemasyarakatan dan hutan tanaman rakyat, karena HD diberikan hak pengelolaan selain izin, sementara yang lain dapat memanfaatkan sumber daya hutan hanya berdasarkan izin. Hutan desa juga dapat dianggap sebagai sarana kompromi untuk memberikan akses kepada masyarakat adat untuk mengelola kawasan hutan, mengingat peraturan mengenai hutan adat masih belum kokoh.

Kelembagaan HD merupakan suatu sistem pengelolaan hutan berbasis masyarakat yang relatif baru yang dirancang oleh Kementerian Lingkungan Hidup dan Kehutanan (KLHK) untuk mengelola kawasan hutan produksi dan hutan lindung yang bebas dari klaim atau hak. Penduduk desa yang diwakili oleh lembaga desa, memainkan peran utama dalam mengelola dan memanfaatkan manfaat dari hutan negara. Dalam hal ini, sebuah desa yang mengelola HD tidak hanya memanfaatkan sumber daya hutan, tetapi juga bertanggung jawab agar hutan tetap lestari. Hutan desa harus berada dalam batas administrasi desa karena menurut Undang-
Undang (UU) Nomor 32 Tahun 2014 Tentang Pemerintahan Daerah, desa didefinisikan sebagai kesatuan masyarakat hukum yang memiliki batas wilayah yang berwenang untuk mengatur dan mengurus urusan Pemerintahan, kepentingan masyarakat setempat berdasarkan prakarsa masyarakat, hak asal usul, dan/atau hak tradisional yang diakui dan dihormati dalam sistem pemerintahan Negara Kesatuan Republik Indonesia (Kementerian Kehutanan, 2014).

Desa melalui lembaga di tingkat desa yang telah mendapatkan izin pengelolaan bisa melakukan komersialisasi kayu, komersialisasi hasil hutan non-kayu, dan jasa lingkungan jika HD adalah hutan produksi (Kementerian Kehutanan, 2014). United Nations Educational, Scientific and Cultural Organization (UNESCO) bekerja sama dengan Kantor Persatuan Bangsa-Bangsa untuk Layanan Proyek The United Nations Office for Project Services (UNOPS) telah memfasilitasi masyarakat dalam membangun Pusat Informasi Lestari (PIL) di Desa Buntoi, Kalimantan Tengah yang diperuntukkan sebagai pusat pembelajaran masyarakat yang diharapkan dapat memperbaiki mata pencaharian masyarakat lokal yang berkelanjutan dan dapat berkontribusi untuk ketahanan terhadap perubahan iklim.

Sebagai tindak lanjut dari Surat Keputusan (SK) Menteri Kehutanan Nomor SK.584/ Menhut-II/2012, Nomor SK.585/MenhutII/2012 dan Nomor SK.586/Menhut-II/2012 tanggal 17 Oktober 2012 tentang Penetapan Kawasan Hutan Lindung sebagai Areal Kerja 
Hutan Desa Buntoi seluas 7.025 hektar, maka Desa Buntoi bersama-sama dengan desa-desa lain yang membentuk Lembaga Pengelola Hutan Desa (LPHD) dan Rencana Kerja Hutan Desa (RKHD). Sejalan dengan itu, UNESCO telah bersama masyarakat mengembangkan Rencana Aksi Komunitas (RAK) untuk Rencana Aksi Pusat Informasi Lestari (PIL) kemudian mengaitkan dengan RKHD. Melalui serangkaian lokakarya, masyarakat dapat mengidentifikasi potensi PIL untuk memfasilitasi kegiatan pengelolaan HD. Informasi dari pengalaman pengelolaan HD, baik terkait dengan perbaikan mata pencaharian maupun dari sudut pandang konservasi akan menjadi pelajaran yang baik yang bisa dibagi melalui PIL.

Hasil Lokakarya RAK untuk PIL menunjukkan bahwa ada keterkaitan dan tumpang tindih kegiatan di RAK untuk PIL dengan RKHD. Beberapa kesamaan yang disorot antara lain adalah dalam penyediaan pengetahuan tentang jasa ekosistem/lingkungan, peningkatan kapasitas untuk mempersiapkan masyarakat untuk pelaksanaan REDD+, agroforestri untuk mata pencaharian berkelanjutan, dan pengelolaan HD.

Salah satu potensi non kayu yang dikembangkan dalam UU Nomor 41 Tahun 1999 adalah pemanfaatan jasa lingkungan, hal tersebut telah dipertegas di dalam Peraturan Pemerintah (PP) Nomor 6 Tahun 2007 Tentang Tata Hutan dan Penyusunan Rencana Pengelolaan Hutan, Serta Pemanfaatan Hutan yang menggantikan PP Nomor 34 Tahun 2002 Tentang Tata Hutan dan Penyusunan Rencana Pengelolaan Hutan, Pemanfaatan Hutan dan Penggunaan Kawasan Hutan. Kegiatan jasa lingkungan yang dapat dilakukan dalam pemanfaatan jasa lingkungan adalah: a) Pemanfaatan jasa aliran air; b) Pemanfaatan air; c) Wisata alam; d) Perlindungan keanekaragaman hayati; e) Penyerapan dan/atau penyimpanan karbon.

Hingga saat ini pengembangan HD di
Desa Buntoi masih dalam tahap awal, dengan demikian banyak kekosongan informasi mengenai kondisi hutan yang meliputi banyak aspek jasa lingkungan seperti carbon stock, kebijakan dan kelembagaan, dan potensi mata pencaharian yang berkelanjutan. Identifikasi jasa ekosistem/ lingkungan HD akan memberikan informasi tentang potensi dan pentingnya hutan, tidak hanya untuk masyarakat di desa tetapi juga untuk penerima manfaat yang lebih luas di tingkat provinsi dan nasional.

Berdasarkan kondisi di atas, telah dilaksanakan penelitian untuk memberikan informasi dan pengetahuan untuk masyarakat pada pengelolaan, pengembangan dan penerapan HD di Desa Buntoi, terutama terkait dengan pemanfaatan jasa lingkungan hutan. Informasi dan pengetahuan yang dihasilkan oleh penelitian ini dapat digunakan oleh masyarakat sebagai bagian dari inisiatif di Pusat Komunikasi Iklim dan Pusat Pembelajaran Masyarakat di Desa Buntoi.

\section{B. TUJUAN PENELITIAN}

Penelitian ini bertujuan untuk mengidentifikasi dan menganalisis potensi jasa lingkungan dari perspektif ilmiah, faktor-faktor yang dapat memengaruhi jasa ekosistem hutan dalam kaitannya dengan dinamika sosial-ekonomi di tingkat masyarakat, dan nilai lingkungan dari jasa ekosistem hutan di HD Buntoi.

\section{METODE PENELITIAN}

Penelitian dilakukan di Desa Buntoi, Kecamatan Kahayan Hilir, Kabupaten Pulang Pisau, Provinsi Kalimantan Tengah selama 2 (dua) bulan pada bulan September sampai dengan Oktober 2013 (Gambar 1). Data yang dikumpulkan meliputi data primer yang diperoleh melalui wawancara dan diskusi dengan pejabat pemerintah, masyarakat, dan lembaga swadaya masyarakat (LSM) di Kabupaten Pulang Pisau terkait dengan 


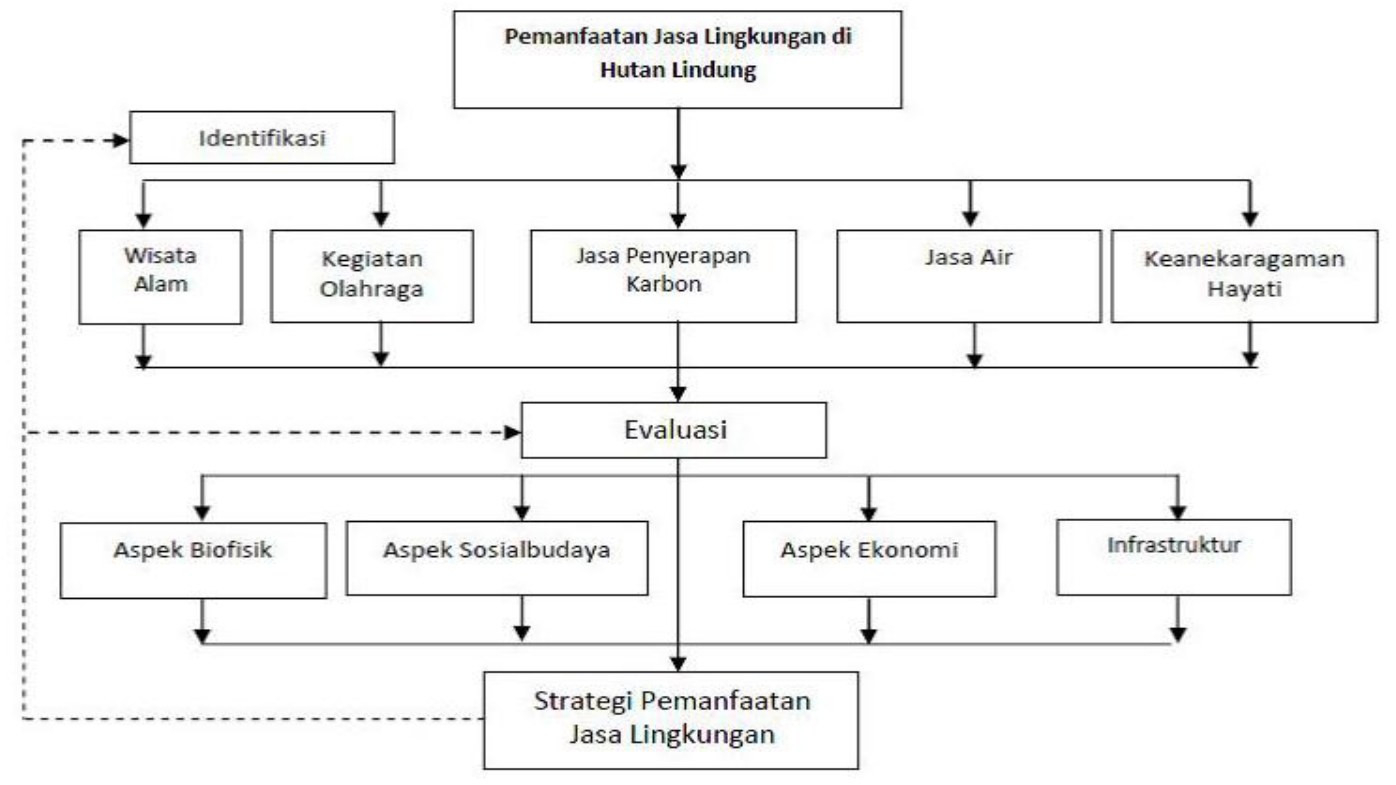

Sumber (Source): Data primer, 2013 (Primary data, 2013)

Gambar 1. Kerangka analisis penelitian pemanfaatan jasa lingkungan di hutan lindung

Figure 1. Analytical framework for researching the utilisation of ecosystem service in protection forest

pemanfaatan jasa lingkungan di HD. Data sekunder diperoleh dari berbagai sumber yang relevan dan berkaitan dengan pemanfaatan hutan lindung dan pengelolaan HD. Data dianalisis secara deskriptif dengan mencermati berbagai kejadian dan aktivitas yang terjadi di wilayah penelitian seperti dalam kerangka analisis (Gambar 1). Analisis potensi jasa ekosistem hutan atau jasa lingkungan difokuskan pada empat kategori yaitu: (1) Jasa air, (2) Penyerapan karbon, (3) Konservasi keanekaragaman hayati, dan (4) Keindahan bentang alam (Mayrand \& Paquin, 2004; Pagiola, Landell-Mills, \& Bishop, 2002).

\section{HASIL DAN PEMBAHASAN}

\section{A. Kondisi Hutan Desa Buntoi}

Ada empat HD dalam satu lanskap yang dikelola oleh empat desa, yakni Buntoi, Mantaren I, Kalawa dan Gohong, namun HD yang terbesar adalah di wilayah Desa Buntoi (Gambar 2). Melalui Keputusan Menteri Kehutanan (Kepmenhut) Nomor SK.586/
Menhut II/2012 Desa Buntoi memiliki wilayah HD sekitar 7.025 ha; dengan dibantu salah satu LSM lokal, POKKER SHK, Desa Buntoi telah membentuk Lembaga Pengelola HD (LPHD) yang berfungsi untuk mengelola potensi HD di wilayah mereka. Desa Buntoi memiliki akses yang baik dari Palangkaraya dan daerah lain di Kalimantan Tengah, serta masih memiliki kawasan hutan relatif baik. Berdasarkan observasi lapangan dan wawancara dengan masyarakat Desa Buntoi, diketahui bahwa kondisi HD Buntoi relatif lebih baik dibandingkan dengan kondisi hutan di sekitarnya. Namun jika ditinjau dari kriteria umum hutan lindung, kondisinya kurang bagus akibat kebakaran hutan dan pembalakan liar yang terjadi sebelum ditetapkan menjadi HD. Potensi kayu yang ada di HD Buntoi antara lain adalah meranti, balau, ramin, pantung, jelutung, belangiran, dan bengaris. Potensi hasil hutan non kayu antara lain adalah tanaman obat dan anggrek hutan. Disamping itu juga ada potensi flora dan fauna seperti rusa, burung sebaru, trenggiling, beruang, monyet ekor pendek/bangkoui, kantong 


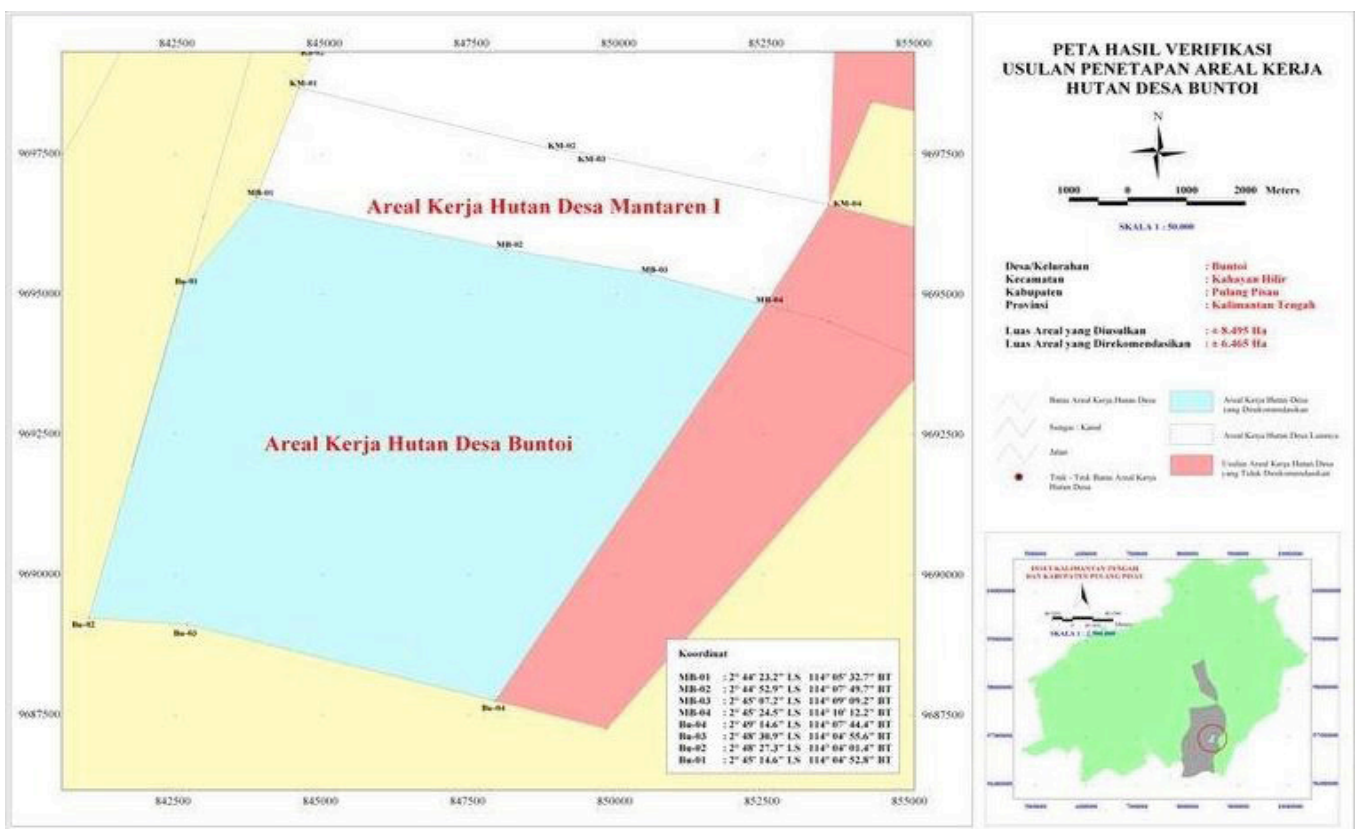

Sumber (Source): Data primer, 2013 (Primary data, 2013)

Gambar 2. Peta hasil verifikasi usulan penetapan areal kerja HD Buntoi

Figure 2. Map of verified working area proposal in buntoi Village Forest

semar, pasak bumi, anggrek hutan, dan jenis obat-obatan yang belum teridentifikasi.

Kondisiinfrastruktur dari pusat Desa Buntoi menuju HD Buntoi belum memadai karena ditempuh dengan jalan kaki dan melalui jalan setapak selama 12 jam tanpa istirahat. Hal tersebut merupakan salah satu kendala dalam pemanfaatan HD Buntoi oleh masyarakat Desa Buntoi, terutama yang berada jauh dari pinggiran hutan. Berdasarkan wawancara dengan penduduk Desa Buntoi, diketahui bahwa tidak ada kelompok masyarakat yang tinggal di pinggiran HD tersebut. Berdasarkan Keputusan Menteri Kehutanan tentang penunjukan Hutan Desa Buntoi, fungsi HD di Desa Buntoi adalah hutan lindung, maka hal tersebut menunjukkan bahwa pemanfaatan hasil hutan kayu sangat terbatas. Sumber daya hutan yang diizinkan untuk digunakan di HD adalah hasil hutan non-kayu seperti jelutung dan rotan, dan jasa lingkungan seperti air, keanekaragaman hayati, keindahan bentang alam dan penyerapan karbon.

\section{B. Potensi Jasa Lingkungan}

Hutan Desa di Buntoi merupakan bagian dari sisa hutan rawa gambut tropis di Provinsi Kalimantan Tengah yang kondisinya relatif baik dibandingkan dengan daerah sekitarnya sehingga HD dapat memberi manfaat ekologi dan ekonomi bagi masyarakat sekitar. Lahan gambut dapat berperan sangat penting dalam penyimpanan karbon dan regulasi air untuk daerah sekitarnya seperti menyeimbangkan pasokan air regional melalui fungsinya sebagai resapan air. Selain itu lahan gambut tropis merupakan reservoir keanekaragaman hayati dan habitat bagi spesies langka, terutama primata seperti orangutan (Pongo pygmaeus) dan beberapa spesies ikan endemik.

Hasil penelitian adalah sebagai berikut: Pertama, hasil analisis biofisik yang dilakukan HD di Desa Buntoi ditemukan bahwa di desa tersebut tidak memiliki sumber air minum yang dapat dimanfaatkan oleh penduduk. Sebagian masyarakat Desa Buntoi yang berada di pinggir Sungai Kahayan menggunakan air rawa yang berwarna coklat untuk digunakan 
kebutuhan sehari-hari termasuk sebagai air minum. Dengan demikian, potensi pamanfaatan jasa air dari HD Buntoi menjadi terbatas.

Kedua, potensipenyerapan dan peyimpanan karbon di HD Buntoi sangat besar karena disamping memiliki potensi vegetasi yang dapat menyerap dan menyimpan karbon, HD Buntoi juga merupakan hutan rawa gambut yang memiliki simpanan karbon besar di bawah tegakan. Jaenicke, Englhart, and Siegert (2011) menyatakan bahwa hutan rawa gambut di hutan tropis dapat menyimpan hingga 20 ton karbon di tanah mineral dan 90\% diantaranya berada di bawah tanah. Proses deforestasi dan kerusakan hutan dapat melepas karbon karena kedua aktivitas tersebut dapat memicu terjadinya dekomposisi atau kebakaran lahan gambut (Olbrei, 2013). Potensi penyerapan karbon tersebut menjadi peluang bagi bangsa Indonesia yang sebagian besar lahan gambutnya berada di Sumatera, Kalimantan dan Papua, termasuk di HD Buntoi. Page, Rieley, and Banks (2011) mengungkapkan bahwa Indonesia memiliki potensi simpanan karbon di lahan gambut tropis terbesar di dunia yang mencapai 57 billion tonnes (Giga tonnes or Gt).

Ketiga, berkenaan dengan potensi keanekaragaman hayati, banyak flora dan fauna yang dapat ditemui di HD Buntoi. Berdasarkan laporan Yayasan Cakrawala Indonesia (2013) dan identifikasi yang dilakukan oleh tim peneliti Badan Penelitian dan Pengembangan Kehutanan Kementerian Kehutanan, beberapa jenis hewan yang masih diburu oleh masyarakat adalah rusa, kancil dan babi. Potensi keanekaragaman hayati tersebut menggambarkan bahwa kekayaan alam yang dimiliki Desa Buntoi yang tidak ternilai harganya dan dapat dimanfaatkan dalam bentuk pemanfaatan hasil hutan nonkayu, objek pariwisata, atau dibudidayakan di tanah milik masyarakat.

Keempat, keindahan bentang alam tidak ditemukan adanya suatu areal yang khas yang dapat dijadikan andalan untuk menarik kedatangan wisatawan ke HD Buntoi. Namun kondisi biofisik HD di desa Buntoi dapat dijadikan objek promosi pariwisata dengan keberadaan satwa dan tumbuhan yang khas seperti orang utan dan kantong semar. Beberapa kegiatan yang cocok dilakukan di HD antara lain observasi dan sebagai stasiun penelitian, potensi sungai dan beberapa hewan buruan seperti rusa dan babi juga dapat dijadikan objek wisata susur sungai atau wisata buru dengan memerhatikan potensi dan kelestariannya karena HD di desa Buntoi sebagai salah satu areal lindung bagi hutan rawa gambut yang ada di wilayah tersebut.

\section{Pengaruh Dinamika Sosial-Ekonomi Masyarakat terhadap Jasa Ekosistem Hutan}

Keberadaan jasa ekosistem atau jasa lingkungan hutan sangat dipengaruhi oleh faktor persepsi para pihak terhadap nilai jasa tersebut, namun kendala utamanya adalah nilai jasa ekosistem hutan sulit untuk diuangkan. Berbeda dengan manfaat hutan yang tampak nyata seperti kayu, rotan, ikan, dan hewan buruan yang dapat dijual dan dikonsumsi, sehingga jasa lingkungan sedikit yang tampak nyata karena bersifat ekesternalitas. Dengan demikian persepsi para pihak atas nilai yang tidak tampak dari jasa lingkungan sangat penting bagi keberadaan hutan tersebut. Banyak pihak yang menganggap bahwa manfaat yang tampak adalah manfaat utama, sehingga keberadaan jasa lingkungan kemungkinan akan terpinggirkan. Sebagai contoh, jika hasil hutan kayu dianggap sebagai satu-satunya hasil hutan yang dapat dimanfaatkan, maka nilai kayu adalah satusatunya nilai dari sumber daya hutan tersebut. Namun jika para pihak juga memperhitungkan nilai lain dari keberadaan hutan seperti nilai karbon hutan, kemudian nilai pohon sebagai habitat dari satwa atau tumbuhan lainnya, maka penebangan kayu akan menghilangkan nilai-nilai yang tidak tampak tersebut.

Di tingkat masyarakat persepsi atas nilai jasa lingkungan mungkin juga dipengaruhi 
Tabel 1. Jenis hewan, komoditas kayu, buah dan sayur, dan jenis tanaman obat Table 1. Types of Wildlife, timber, fruits and vegetables, and medicinal plants

\begin{tabular}{|c|c|}
\hline $\begin{array}{l}\text { Kelompok } \\
\text { (Group) }\end{array}$ & $\begin{array}{l}\text { Nama Jenis } \\
\text { (Species) }\end{array}$ \\
\hline Hewan (Wildlife) & $\begin{array}{l}\text { Rusa, babi, kancil, biawak, ular sanca, kalawet / uwa-uwa, kahiu / urang utan, } \\
\text { bakei/kera, bakara/bakantan, kalasi, macan dahan, sabaru, keruang, karahau, } \\
\text { burung tingan, burung baliang ahas, burung kak, hanjaliwan, talisuk, burung betet, } \\
\text { burung murai, burung punai, burung tabuan, burung takukur, burung tiung, burung } \\
\text { bakaka, burung mangkung, burung bubut, burung tampalu, burung ampit, kawuk, } \\
\text { tekngok, pusa kambe / kucing hutan, kukang, burung tabengkong, burung balatok. }\end{array}$ \\
\hline $\begin{array}{l}\text { Komoditas Kayu } \\
\text { (Timber) }\end{array}$ & $\begin{array}{l}\text { Merang (ramin), meranti, lanan binti, kahui / belangiran, lanan panaga, kambalitan, } \\
\text { alau, tarantang, keput bajuku, tanah-tanah/tumih, Lewang, nyatu bawui, hatangan, } \\
\text { papong, bangaris, rasak danum, bangkirai sabun, gemor, salombar, nyatu undus, } \\
\text { panaga jangkar, hanjalutung / polantan / pulai, ramin / merang, totup kabala, ehang, } \\
\text { kambarisa, garonggang, payait, gantalang, mahang, kayu tantimun, balawan, } \\
\text { tamehas }\end{array}$ \\
\hline $\begin{array}{l}\text { Buah dan sayur } \\
\text { (Fruit and vegetable) }\end{array}$ & $\begin{array}{l}\text { Umbut rotan, kelakai/pakis, bajei/pakis, jamur kuping, jamur tiram, jamur } \\
\text { merang, jamur lokal kulat bantilung, kulat siaw }\end{array}$ \\
\hline $\begin{array}{l}\text { Tanaman obat } \\
\text { (Medical plant) }\end{array}$ & $\begin{array}{l}\text { Hanur kuning / akar kuning, kalanis (akar rambat), galas sangumang / kantong } \\
\text { semar, bajakah kalalawit }\end{array}$ \\
\hline
\end{tabular}

Sumber (Source): Pengolahan data primer dan sekunder, 2013 (Processed from primary and secondary data, 2013)

oleh kebutuhan atas sumber daya hutan untuk kehidupan sehari-hari. Bagi masyarakat yang menggantungkan hidupnya pada pemanfaatan hasil hutan kayu dan bukan kayu seperti rotan dan gemor, maka keberadaan sumber daya hutan yang tampak merupakan satu-satunya sumber penghidupan bagi mereka. Terlebih jika mereka berada pada kondisi miskin. Dengan demikian, pentingnya jasa lingkungan menjadi terabaikan oleh banyak pihak termasuk masyarakat lokal sendiri. Selain itu keberadaan pasar untuk jasa lingkungan dapat memengaruhi persepsi mereka sehingga jika tidak ada permintaan atas jasa lingkungan, maka jasa lingkungan tersebut menjadi tidak bernilai.

Faktor yang lain berpengaruh terhadap keberadaan jasa lingkungan hutan yaitu adanya kebijakan yang mendukung. Faktor kebijakan ini sangat penting karena dapat memberikan insentif pada pemanfaatan jasa lingkungan hutan. Sebagai contoh, pemanfaatan karbon hutan mungkin dapat dilaksanakan jika pemerintah memberlakukan peraturan perdagangan karbon dengan mekanisme yang dapat dilakukan di tingkat lokal dan melibatkan para pihak seperti perusahaan lokal dan masyarakat lokal. Contoh lainnya adalah bioprospecting untuk keanekaragaman hayati. Upaya mencari manfaat nyata dari tumbuhan dan hewan yang ada di hutan untuk kepentingan umum, seperti penyediaan obat yang murah dan berkualitas, dapat dilakukan dengan cara bioprospecting yang perlu dukungan kebijakan pemerintah agar kerja sama antar pihak seperti swasta, akademisi, dan masyakarat lokal memberikan manfaat yang nyata bagi pemanfaatan jasa hutan.

Kebijakan pemerintah telah banyak yang dikeluarkan melalui peraturan mengenai pemanfaatan jasa lingkungan hutan termasuk isu konservasi karbon hutan dalam kerangka Reducing Emmisionsfrom Deforestation and Forest Degradation in Developing Countries 
Tabel 2. Pengetahuan, kepentingan dan pengalaman masyarakat terhadap jasa lingkungan Table 2. Knowledge, interest, and experiences of community on ecosystem services

\begin{tabular}{cll}
\hline No. & \multicolumn{1}{c}{ Pertanyaan (Questions) } & \multicolumn{1}{c}{ Respon (Responses) } \\
\hline 1. & Pengetahuan terkait program konservasi & Sebagian besar peserta tidak tahu \\
2. & Pengetahuan tentang pentingnya konservasi hutan & Sebagian peserta tidak faham \\
3. & Pengetahuan tentang jasa air & Sebagian besar peserta tahu \\
4. & Pengetahuan tentang keanekaragaman hayati & Tidak ada peserta yang tahu \\
5. & Pengetahuan tentang keindahan alam & Sebagian peserta tahu \\
6. & Pengetahuan tentang penyerapan karbon & Tidak ada peserta yang tahu \\
7. & Pengetahuan tentang Pembayaran Jasa Lingkungan & Tidak ada peserta yang tahu \\
& (PJL) & \\
8. & Keinginan untuk ikut program PJL & Semua peserta tertarik \\
9. & Pengalaman dengan pembayaran dari pemerintah & Semua peserta memiliki \\
& & pengalaman \\
\hline
\end{tabular}

Sumber (Source): Data primer, 2013 (Primary data, 2013)

(REDD+). Keberadaan jasa lingkungan hutan sudah mendapatkan dukungan kebijakan dan peraturan perundang-undangan di tingkat nasional, namun masih belum banyak ditemui adalah peraturan daerah yang mendorong untuk pemanfaatan jasa ekosistem hutan secara lebih baik. Dengan demikian persepsi para pihak, terutama masyarakat sekitar hutan terhadap keberadaan dan manfaat jasa lingkungan hutan menjadi sangat penting untuk diketahui karena berkaitan dengan bagaimana jasa lingkungan dapat dimanfaatkan bagi kesejahteraan mereka. Dengan memahami sejauh mana pengetahuan masyarakat akan jasa hutan, maka strategi pemanfaatan jasa lingkungan hutan dapat dirumuskan dengan lebih baik dan sesuai dengan kapasitas masyarakat.

Tabel 2 menggambarkan pengetahuan masyarakat tentang isu-isu konservasi dalam pelestarian hutan, dan pengalaman mereka dalam berurusan dengan pembayaran dari pemerintah melalui berbagai program. Hasil analisisis menunjukkan bahwa dalam hal program konservasi, sebagian besar masyarakat di lokasi penelitian tidak tahu apa saja program konservasi yang telah dilaksanakan di daerah mereka. Akan tetapi beberapa masyarakat yang terlibat dalam penelitian ini menyadari manfaat konservasi hutan, meskipun mereka mungkin tidak mengutamakan konservasi hutan ketika harus membandingkan manfaat tak nyata dengan manfaat nyata dari ekstraksi kayu, pemanfaatan hasil hutan non-kayu, atau konversi hutan menjadi perkebunan kelapa sawit.

Mengenai keberadaan jasa lingkungan di HD, sebagian besar masyarakat yang terlibat dalam penelitian ini mengerti tentang manfaat hutan untuk jasa air dan beberapa dari mereka tahu tentang keindahan bentang alam. Namun, masyarakat tidak mengerti tentang keanekaragaman hayati dan penyerapan karbon sebagai jasa lingkungan hutan. Sehubungan dengan isu penyerapan karbon, semua masyarakat tidak mengerti bahwa hutan dapat menyerap karbon. Ini adalah situasi umum karena masalah emisi dan penyerapan karbon relatif baru dan masyarakat umum membutuhkan latar belakang pendidikan yang memadai untuk dapat memahaminya. Bahkan di negara-negara maju pun masih banyak ditemui masyarakat yang tidak tahu tentang emisi dan penyerapan karbon.

Sebagian besar masyarakat di lokasi penelitiantidak tahu tentang pembayaran untuk konservasi hutan atau Payment for Ecosistem Services (PES). Namun, mereka telah memiliki pengalaman dengan pembayaran 
dari pemerintah, seperti pembayaran langsung tunai (BLT) yang bertujuan untuk mengkompensasi orang miskin dampak dari pengurangan subsidi bahan bakar minyak (BBM) (President of Indonesia, 2008), dan program pemberdayaan masyarakat, seperti Program Nasional Pemberdayaan Masyarakat (PNPM) Mandiri yang bertujuan meningkatkan kesejahteraan dan kesempatan kerja masyarakat miskin melalui hibah dan bantuan teknis (PNPM Mandiri, 2009).

Hasil wawancara menunjukkan bahwa hingga saat ini manfaat langsung keberadaan HD belum dirasakan oleh warga Desa Buntoi. Hal ini disadari oleh warga karena pemanfaatan HD baru pada tahap penyusunan rencana kelola dan rencana tindak lanjut. Mereka menyatakan bahwa manfaat tidak langsung mereka peroleh dari HD di wilayah mereka seperti perhatian dan bantuan dalam peningkatan kapasitas individu dan kelembagaan dari berbagai pihak baik dalam skala nasional maupun internasional.

\section{Strategi Pemanfaatan Jasa Lingkungan di HD Buntoi}

Studi ini tidak melakukan analisis biayamanfaat untuk pemanfaatan jasa lingkungan di HD karena batas-batas dan potensi HD masih sedang dibentuk dan disurvei. Namun, dengan menggunakan data yang dikumpulkan oleh Yayasan Cakrawala Indonesia (2013) mekanisme pemanfaatan jasa lingkungan di HD dapat dirancang. Terdapat dua kegiatan utama yang dapat dirancang yaitu: 1). Kegiatan ekowisata, 2).Kegiatan konservasi karbon.

Kegiatan ekowisata dilakukan dengan memanfaatkan dan mengembangkan keanekaragaman hayati dan keindahan bentang alam yang ada di HD melalui otoritas HD. Kegiatan dapat menawarkan paket wisata seperti bird wathcing, melihat orang utan dan rusa, memancing di sungai dan kanal di dalam dan sekitar hutan, pembuatan kanopi trail, dan pertunjukan budaya oleh suku dayak. Konservasi karbon dapat dirancang melalui program REDD+. Pemanfaatan jasa lingkungan dapat dilakukan melalui Pembayaran Jasa Lingkungan (PJL). Dalam skema PJL, penyedia jasa lingkungan yang sah harus dikompensasi untuk biaya yang terkait dengan penyediaan jasa, dan orang-orang yang mendapatkan manfaat dari layanan ini harus membayar untuk layanan ini, sehingga manfaat dari jasa lingkungan dapat diinternalisasikan. Dalam merancang PJL, keamanan penyediaan jasa yang berhubungan dengan hak atas sumber daya harus dipertimbangkan. Para penyedia jasa akan terus memberikan pelayanan jika ada cukup insentif untuk mempertahankan transaksi dengan pembeli, jika pembeli menemukan pilihan yang lebih baik untuk penggunaan lahan. Berikut ini dipaparkan strategi pemanfaatan jasa lingkungan di HD Buntoi:

\section{Pengembangan Ekowisata}

Salah satu kegiatan yang diperbolehkan dalam hutan lindung adalah kegiatan yang berbasis pariwisata, yang dikenal di Indonesia sebagai wisata alam. Pariwisata berbasis alam adalah perjalanan sukarela dan sementara atau bagian dari perjalanan untuk menikmati keunikan dan keindahan alam. Pemerintah Indonesia menggunakan istilah "wisata alam", bukan "ekowisata" dalam peraturan apapun. Istilah ekowisata umumnya digunakan oleh akademisi dan praktisi pariwisata. Menurut mereka, ekowisata memiliki makna yang sedikit berbeda dengan pariwisata berbasis alam (wisata alam).

Pengembangan ekowisata di HD harus mempertimbangkan konservasi sumber daya alam, partisipasi masyarakat lokal, dan kemitraan dengan pihak. Ada enam aspek dalam perkembangan alam berbasis pariwisata di HD, termasuk: (1) Pengembangan pariwisata di tingkat nasional dan daerah, (2) Rencana lokasi HD, (3) Pengelolaan lingkungan hidup; (4) Kondisi sosial, ekonomi dan budaya masyarakat setempat; (5) Perencanaan tata ruang; dan (6) Peraturan 
yang memadai.

Hasil dari pengembangan ekowisata di HD dipengaruhi oleh: (1) Kejelasan tentang lokasi wisata di taman (isu batas dan zonasi); (2) Dukungan program yang disediakan oleh pemerintah, LSM, dan pihak lain yang terkait; (3) Komitmen para pihak untuk melaksanakan program; (4) Pemahaman masyarakat setempat tentang wisata, pariwisata, dan jasa mereka; (5) Perilaku masyarakat setempat terhadap wisatawan; (6) Distribusi pekerjaan dan pendapatan; (7) Jumlah wisatawan; (8) Penerimaan sosial; (9) Pemasaran dan promosi; dan (10) Kemampuan masyarakat setempat.

Masyarakat lokal harus terlibat dalam ekowisata karena: (1) Tidak dapat diterima jika ada masyarakat dan mereka bukan bagian dari proses; (2) Berdasarkan definisinya, masyarakat lokal adalah bagian utama yang harus terlibat; dan (3) Jika masyarakat setempat tidak terlibat maka akan cenderung menimbulkan konflik.

Tantangan utama pengembangan ekowisata di HD Buntoi adalah masalah infrastruktur yang masih kurang mendukung untuk menarik wisatawan agar berkunjung ke HD Buntoi. Namun demikian, wisata berbasis aktivitas seperti memancing atau yang berbasis penelitian dapat dijadikan salah satu langkah awal membangun ekowisata di HD Buntoi. Dalam hal ini dukungan dari pemerintah daerah sangat diperlukan mengingat sumber daya di Desa Buntoi sangat terbatas. Bahkan dalam wawancara dengan penduduk Desa Buntoi ditemui bahwa sebagian besar warga desa tidak mengerti potensi wisata apa yang dapat ditawarkan dari HD Buntoi. Namun demikian, pelatihan yang dilakukan oleh Yayasan Cakrawala Indonesia dan didukung oleh UNESCO mengenai ekowisata telah membuka kesadaran beberapa warga desa atas potensi pariwisata di daerah mereka.

Di tingkat kabupaten dan provinsi, sebagian besar para pihak yang diwawancarai dalam penelitian ini masih belum mengetahui keberadaan HD dan potensinya yang ada di Desa Buntoi. Namun demikian, para pihak menyatakan bahwa mereka akan bersedia berwisata ke HD Buntoi jika telah dikembangan objek wisata yang memang menarik, dan infrastruktur yang memadai telah tersedia, terutama akses jalan darat. Dalam hal ini keberadaan rumah adat dan Pusat Informasi Lestari di Desa Buntoi dapat menjadi salah satu upaya menarik kedatangan wisatawan ke Desa Buntoi yang pada akhirnya akan membantu pengembangan ekowisata di HD Buntoi.

\section{Konservasi Karbon Hutan}

Lembaga Pengelola Hutan Desa (LPHD) dapat mengusulkan suatu kegiatan dalam rangka Pengurangan Emisi dari Deforestasi dan Degradasi Hutan (REDD+) yang kini sedang dipersiapkan oleh pemerintah pusat dan daerah. Keberadaan HD merupakan salah satu upaya untuk memperkuat tenurial hutan yang mendukung implementasi REDD+. Mengenai efektivitas biaya REDD+, keberadaan HD dapat mengurangi biaya transaksi dan penyediaan jasa lingkungan. Selanjutnya, dalam merancang mekanisme distribusi manfaat REDD+ di desa hutan, perlu dilakukan evaluasi apakah pengelola HD dapat memenuhi kriteria PJL, yaitu: (1) Persyaratan; (2) Nilai tambah; (3) Transparansi, dan (4) Kesukarelaan.

Sehubungan dengan transaksi (persyaratan) dalam REDD+, LPHD sebagai pengelola HD dapat menjadi lembaga resmi untuk melakukan kontrak bersyarat dengan pembeli karbon hutan. Dalam hal ini LPHD juga bertanggung jawab untuk pencapaian kinerja HD dalam penyerapan karbon hutan dan penyimpanan stok karbon hutan sebagaimana diatur dalam kontrak pembayaran jasa lingkungan. Studi terkini mengenai mekanisme PJL dalam kaitannya dengan implementasi REDD+ telah dilaksanakan oleh Ginoga et al. (2011). Tabel 3 memaparkan beberapa hal yang dapat dipelajari dari beberapa kegiatan PJL untuk merancang implementasi REDD + di Indonesia. 
Tabel 3. Hikmah pembelajaran PJL untuk desain imeplementasi REDD+ di Indonesia Table 3. Learning from PJL for REDD + design implementation in Indonesia
No. Mekanisme pembayaran
(Mecanism of payment)
Hikmah pembelajaran (Lessons learn)

1. Amazon Fund

2. Socio Bosque

3. Lombok Barat

4. Cidanau Banten

5. Climate Change Forests and Peatlands in Indonesia (CCFPI)

6. Micro hydro

7. BDS Viet Nam
- Mekanismenya sederhana.

- Cocok untuk voluntary market.

- Wadah untuk peserta (benefeciaries) menampung masyarakat adat dan/atau lokal, juga peserta individu.

- $\quad$ LSM tingkat lokal, kompeten dan bertanggung jawab.

- Memberikan insentif tidak hanya pada penanaman pohon baru, tapi juga pada penjagaan terhadap tanaman yang sudah ada.

- Untuk masyarakat adat dan/atau lokal penggunaan dananya melalui "investment plan" (kesehatan, pendidikan, transportasi, pembayaran gaji untuk jagawana).

- Skala nasional.

- Melibatkan kementerian kehutanan dan kementerian keuangan.

- Prosedur, aturan main, hak dan kewajiban, sanksi, pemantauan, besarnya insentif, dan lamanya kontrak diatur dengan jelas.

- Ada lembaga daerah yang menjadi perantara antara peserta dengan pemerintah.

- Wadah untuk peserta (beneficiaries) menampung masyarakat adat dan/atau lokal, serta peserta individu.

- Untuk masyarakat adat dan/atau lokal penggunaan dananya melalui "social investment" (kesehatan, pendidikan, infrastruktur).

- $\quad$ Pembagian persentase manfaat kepada: pengelola, pusat, provinsi, dan kabupaten jelas.

- Prosesnya melibatkan pemangku kepentingan yang cukup komprehensif.

- Konsultasi publik dan pemerintah terencana dengan baik.

- Menginisiasi dengan aturan-aturan (peraturan daerah).

- Bersifat sukarela (voluntary).

- Ada forum yang menjadi perantara (FKDC) yang dibentuk atas dukungan pemerintah (surat keputusan Gubernur).

- Basis luas lahan dan jumlah pohon menjadi ukuran besaran insentif.

- Mekanisme cukup sederhana.

- Hak dan kewajiban peserta jelas.

- Pendampingan oleh LSM lokal dilakukan untuk menjembatani LSM pusat dengan peserta.

- Pemda/dinas terkait ikut terlibat dalam pembinaan peserta.

- Inisiasi dilakukan dari tingkat bawah ke atas (bottom-up), sehingga lebih bertahan.

- Pembagian persentase manfaat atau laba jelas.

- Masyarakat yang tidak mampu menjadi sasaran utama penerima manfaat.

- LSM dan lembaga desa berperan aktif.

- Kondisi Vietnam terutama secara ekonomi tidak berbeda jauh dengan Indonesia

- Memberikan hikmah pembelajaran mekanisme yang bersifat compliant.

Sumber (Source): Ginoga et al., 2011 
Hutan Desa harus mampu memberikan manfaat tambahan (additionality) karbon dari pengurangan emisi hutan yang dapat menjadi dasar pembayaran jasa lingkungan. Karena HD adalah hutan lindung dimana pemanfaatan kayu sangat terbatas, dapat dikatakan bahwa additionality desa hutan dalam pengurangan emisi karbon relatif rendah. Namun, jika kondisi saat ini hutan adalah HD terdegradasi, upaya rehabilitasi HD dengan penanaman akan dapat dikategorikan sebagai upaya untuk meningkatkan cadangan karbon, sehingga meningkatkan additionality HD.

Adanya LPHD yang juga diartikan sebagai lembaga kolaborasi, diharapkan pelaksanaan REDD+ dapat dilaksanakan secara transparan karena LPHD adalah lembaga yang memiliki legitimasi yang kuat dalam mengelola HD, baik dalam administrasi maupun pengelolaan hutan. Akhirnya, implementasi REDD+ sangat tergantung pada kesukarelaan dari pengelola HD untuk berpartisipasi atau tidak dalam skema REDD+. Terkait dengan prinsip kesukarelaan dalam PJL, maka pengelola HD harus merasa mendapatkan manfaat yang minimal sama dengan pengelolaan HD yang selama ini dilaksanakan. Jika tidak, maka pengelola HD memiliki pilihan untuk tidak mengikuti skema PJL untuk REDD+.

Sesuai dengan prinsip-prinsip efisiensi ekonomi, pembayaran REDD+ harus didasarkan pada peningkatan volume karbon yang dapat diserap atau ditahan oleh HD dalam jangka waktu tertentu (Muttaqin, 2012). Namun, dengan tidak adanya standar harga karbon untuk kegiatan REDD+ saat ini, maka nilai karbon masih sulit untuk didapatkan. Oleh karena itu, biaya korbanan (opportunity cost) dapat digunakan sebagai pendekatan. Biaya korbanan adalah biaya yang timbul karena orang tidak bisa lagi memperoleh penghasilan dari HD sebagaimana seharusnya. Dalam kasus ini, total pendapatan yang hilang dibagi dengan volume pengurangan emisi karbon adalah harga karbon minimum yang dapat diterima oleh masyarakat untuk berpartisipasi dalam kegiatan REDD+.
Saat ini pendapatan orang-orang di desa-desa sekitar hutan didukung oleh pengelolaan kebun karet di dalam dan sekitar HD. Dengan pelaksanaan skema REDD+, masyarakat mungkin tidak boleh melakukan peremajaan kebun karet dalam kurun waktu kontrak REDD+ karena akan menghasilkan emisi. Kondisi ini dapat memengaruhi produktivitas tanaman karet dan yang akhirnya akan mengurangi pendapatan masyarakat. Oleh karena itu, pembayaran REDD+ dapat didasarkan pada pengurangan pendapatan yang dialami oleh masyarakat karena keterlambatan penanaman kembali. Studi Yayasan Cakrawala Indonesia (2013) menunjukkan bahwa pendapatan bersih dari kebun karet rakyat mencapai Rp1.445.750/ bulan. Dengan demikian pengelola HD dapat mendasarkan negosiasi PJL dengan pembeli jasa berdasarkan pendapatan masyarakat dari kebun karet tersebut.

Kegiatan yang berpotensi untuk mengurangi emisi karbon antara lain dari upaya menunda peremajaan kebun karet, sehingga kebun karet tersebut dapat menjerap dan menyimpan karbon hutan lebih lama. Jika masyarakat didorong untuk memperlama proses peremajaan kebun karet baik melalui sistem tebas-bakar maupun sisipan, maka mereka harus mendapatkan kompensasi atas penurunan kuantitas dan kualitas sedapan karet hingga batas waktu tanaman karet tersebut tidak menghasilkan lagi.

Kelembagaan distribusi manfaat REDD+ di HD dengan menggunakan mekanisme PJL perlu dirancang dengan meminimumkan biaya transaksi dan mendorong masyarakat untuk mengikuti program PJL untuk REDD + tersebut. Upaya untuk menekan biaya transaksi, maka mekanisme PJL untuk REDD+ ini menggunakan sistem government-financed PJL, dimana pemerintah pusat mengkoordinasikan dana-dana dari pembeli internasional/nasional, sementara pemerintah daerah mengkoordinasikan danadana dari pembeli lokal (Muttaqin, 2012). Pemerintah pusat kemudian mengirimkan 


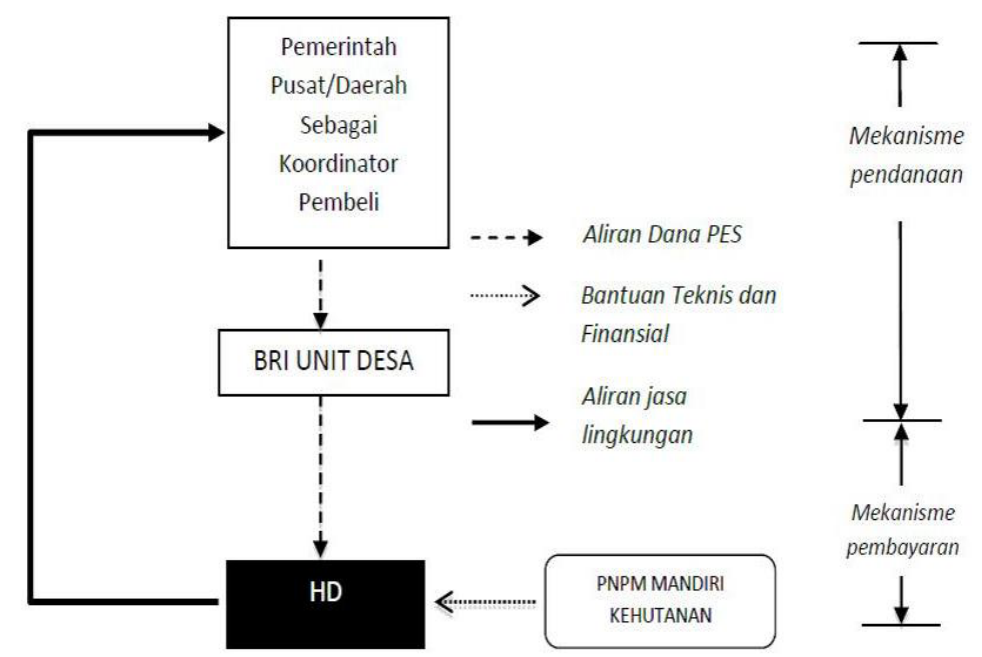

Sumber (Source): Muttaqin, 2012

Gambar3. Kerangka kelembagaan PJL untuk REDD+ di HD Buntoi dimodifikasi dari Muttaqin (2012)

Figure 3. Institutionalising framework for PES for REDD+ at Buntoi Village Forest modified from Muttaqin (2012)

dana-dana tersebut ke pemerintah daerah melalui mekanisme kebijakan fiskal. Dengan demikian, para pengelola HD nantinya akan menghadapi pasar monopsoni sehingga lebih efisien karena tidak perlu berhubungan dengan banyak pembeli yang justru akan merepotkan dan meningkatkan biaya transaksi. Gambar 3 memaparkan rancangan kelembagaan PJL untuk REDD+ di HD. Rancangan kelembagaan ini dimodifikasi dari studi Muttaqin (2012).

Agar efisiensi dan efektivitas mekanisme PJL untuk REDD + terjaga, pemerintah dapat menunjuk lembaga keuangan lokal yang sudah ada dan memiliki kredibilitas tinggi, seperti Bank BRI unit Desa, sebagai pengelola dana REDD+ (lihat Gambar 3). Sehingga tidak perlu lagi membentuk unit pengelola dana REDD+ baru yang akan meningkatkan biaya transaksi. Bank BRI unit Desa inilah yang nanti akan berhubungan langsung dengan pengelola HD dalam proses transaksi penyediaan jasa karbon hutan berdasarkan kontrak yang telah disepakati antara pengelola HD dan pemerintah sebagai 'pembeli' jasa.

Di samping keberadaan lembaga keuangan lokal, maka yang tidak kalah pentingnya adalah keberadaan lembaga atau program lokal untuk membantu pengelola HD dalam persiapan dan pelaksanaan PJL untuk REDD +. Sebagaimana telah dibahas di bagian terdahulu, PJL untuk REDD+ harus mampu memberikan insentif kepada masyarakat pengelola HD untuk berpartisipasi dalam program REDD+ secara sukarela. Namun demikian ada satu hal yang mungkin menjadi kendala utama pelaksanaan REDD + dengan melibatkan masyarakat, yaitu ketersediaan data stok karbon di HD, baik berupa baselines, maupun tingkat pengurangan emisinya. Jika pengelola HD sendiri diminta untuk melakukan pengukuran dan pemantauan karbon dengan dana dari pengelola HD, maka justru akan menjadi disinsentif bagi pengelola HD tersebut. Oleh karena itu, perlu dirancang adanya pendanaan lain di luar program PJL untuk REDD+ untuk membantu masyarakat melakukan pengukuran dan pemantauan stok karbon di HD. Salah satu program yang dapat diikutsertakan dalam program PJL untuk REDD + adalah Program Nasional Pemberdayaan Masyarakat Mandiri (PNPM 
Mandiri) di bidang kehutanan.

Penerbitan Peraturan Menteri Kehutanan (Permenhut) Nomor P.16/Menhut-II/2011 tentang Pedoman Umum Program Nasional Pemberdayaan Masyarakat Mandiri Kehutanan memungkinkan dilaksanakannya programini untuk membantumayarakat sekitar HD melakukan kegiatan pengukuran dan pemantauan karbon hutan. Dengan demikian, masyarakat tidak perlu mengeluarkan biaya tambahan untuk mengikuti PJL untuk REDD + karena biaya dan bantuan teknis persiapan pelaksanaan PJL untuk REDD+ sudah disediakan oleh pemerintah melalui PNPM Mandiri Kehutanan. Hal ini juga akan membantu program pengentasan kemiskinan di sekitar desa hutan yang pada akhirnya dapat meningkatkan pemerataan program PJL untuk REDD+ karena masyarakat miskin juga akan dapat berpartisipasi dalam program tersebut. Masyarakat Desa Buntoi telah berpengalaman dalam pengelolaan program PNPM Mandiri, sehingga dapat menjadi salah satu kekuatan untuk menjalankan program ini terkait dengan konservasi karbon HD.

Institusi utama yang dapat memastikan pembagian manfaat yang adil bagi seluruh warga masyarakat desa di sekitar HD adalah LPHD agar dapat mengurangi biaya transaksi dengan pembeli jasa (baik pemerintah, swasta maupun LSM). Sebaiknya LPHD menjadi koordinator bagi seluruh warga desa yang memiliki hak atas karbon yang tersimpan dalam atau diserap oleh HD dan kebun karet. Pendapatan dan manfaat dari transaksi pengurangan emisi karbon tersebut kemudian didistribusikan kepada warga desa berdasarkan kehilangan pendapatan masing-masing warga karena keberadaan proyek REDD+. Hal ini dilakukan untuk menumbuhkan rasa memiliki terhadap LPHD sebagai institusi tingkat paling kecil dalam mengelola hutan (Ekawati, Ginoga, \& Lugina, 2013).

Program REDD+ perlu disikapi dengan bijak dan penuh perhitungan, karena tidak semua aktivitas layak untuk memperoleh pembayaran dari REDD+. Lebih dari itu, analisis biaya dan manfaat perlu dilakukan agar REDD+ tidak malah menjadi beban bagi masyarakat karena biaya yang dikeluarkan lebih tinggi dari pada manfaat yang diterima dari pembayaran REDD+. Sebagai contoh, sebuah kebun karet dapat menyerap karbon dioksida di atmosfer sebesar 272,08 ton/ha selama daur 30 tahun produksi (The International Rubber Research \& Development Board, 2012), namun jika kebun karet ini dibangun dengan menebang hutan alam maka emisi yang dihasilkan dari penebangan hutan alam adalah sekitar 100150 ton/ha, dan akan lebih besar lagi jika yang ditebang adalah hutan rawa gambut (Blaustein et al., 2007). Sehingga tidak semua potensi penyerapan karbon dari hutan karet selama 30 tahun dapat dikompensasi, karena yang dikompensasi oleh proyek REDD+ adalah selisih antara sebelum dan sesudah suatu penggunaan lahan. Jika harga karbon hutan per ton tidak mampu mengkompensasi biaya untuk membangun kebun karet, maka hanya akan menjadi beban bagi perkebunan karet rakyat.

\section{KESIMPULAN DAN SARAN}

\section{A. Kesimpulan}

Studi tentang pemanfaatan jasa lingkungan hutan di Desa Buntoi, Kecamatan Kahayan Hilir, Kabupaten Pulang Pisau, Provinsi Kalimantan Tengah menunjukkan bahwa ada dua jenis kegiatan yang dapat dikembangkan untuk memanfaatkan keanekaragaman hayati, keindahan bentang alam, dan konservasi karbon di desa hutan yaitu: (1) Kegiatan ekowisata berbasis masyarakat; dan (2) Skema REDD+.

Tantangan yang dihadapi berkaitan dengan kegiatan ekowisata yaitu masalah infrastruktur lokasi HD yang perlu perhatian serius dari pemerintah kabupaten dan provinsi terkait dengan pembangunan wilayah. Selain itu masalah pengetahuan dan keahlian masyarakat setempat dalam mengelola kegiatan wisata yang perlu diupayakan 
pelatihan secara berkelanjutan seperti yang pernah dilaksanakan melalui bantuan UNESCO.

\section{B. Saran}

Desain kelembagaan PJL untuk REDD+ di HD yang diusulkan dalam penelitian ini yaitu dengan menciptakan sistem distribusi manfaat yang mampu: (1) Mengkompensasi biaya korbanan (biaya yang telah banyak dikeluarkan) masyarakat pengelola HD, (2) Menumbuhkan kesadaran konservasi sumber daya hutan, (3) Meningkatkan kapasitas masyarakat, dan (4) Memungkinkan partisipasi yang luas dari seluruh lapisan masyarakat. Sehingga desain kelembagaan tersebut dapat mendukung prinsip-prinsip efisiensi, efektivitas, kelestarian dan keadilan dalam pengelolaan sumber daya hutan.

\section{UCAPAN TERIMA KASIH (ACKNOWLEDGEMENT)}

Terimakasih disampaikan kepada warga Desa Buntoi yang terlibat dalam penelitian ini dan kepada UNESCO yang telah mendukung pendanaan kegiatan ini.

\section{DAFTAR PUSTAKA}

Blaustein, R., Ettlinger, R.B., Boucher, D., Macey, K., Ryan, F., \& Schwartzman, S. (2007). Reducing emissions from deforestation and forest degradation (REDD). Washington, DC: Climate Action Network

Ekawati, S., Ginoga, K.L., \& Lugina, M. (2013). Kondisi tata kelola hutan untuk implementasi pengurangan emisi dari deforestasi dan degradasi hutan (REDD+) di Indonesia. Jurnal Analisis Kebijakan Kehutanan, 10(1), 72-87.

Ginoga, K.L., Sumedi, N., Djaenudin, D., Nurfatriani, F., Indartik, \& Lugina, M. (2011). Analisis keuntungan dan kendala mekanisme pembayaran jasa lingkungan untuk mendukung keberhasilan implementasi mekanisme REDD+. Bogor: Pusat Penelitian dan Pengembangan Perubahan Iklim dan Kebijakan.
Jaenicke, J., Englhart, S., \& Siegert, F. (2011). Monitoring the effect of restoration measures in Indonesian peatlands by radar satellite imagery. Journal of Environmental Management, 92(3), 630-638. doi: http:// dx.doi.org/10.1016/j.jenvman.2010.09.029

Kalimantan Forests and Climate Partnership. (2014). Peta rencana pola tata guna lahan Desa Katimpun. Kapuas: Kapuas Australia Forest Carbon Partnership (IAFCP) melalui Program Kalimantan Forests and Climate Partnership (KFCP) bekerja sama dengan Pemerintah Kabupaten Kapuas dan Desa Katimpun.

Peraturan Menteri Kehutanan Nomor P.89/MENHUTII/2014 Tentang Hutan Desa.

Mayrand, K. \& Paquin, M. (2004). Payments for environmental services: $A$ survey and assessment of current schemes (pp. 53). Montreal: Unisfera.

Muttaqin, M.Z. (2012). Designing payments for environmental services (PES) to reduce emissions from deforestation and forest degradation (REDD+) in Indonesia. (PhD Thesis). Canberra: The Australian National University.

Olbrei, Erik. (2013, 25 September). Indonesia sets a carbon time-bomb. Retrieved 1 October, 2013, from http://theconversation.com/ indonesia-sets-a-carbon-time-bomb-17216

Page, S.E., Rieley, J.O. \& Banks, C.J. (2011). Global and regional importance of the tropical peatland carbon pool. Global Change Biology, 17(2), 798-818. doi: 10.1111/j.13652486.2010.02279.x

Pagiola, S., Landell-Mills, N., \& Bishop, J. (2002). Market-based mechanisms for forest conservation and development. In S. Pagiola, J. Bishop \& N. Landell-Mills (Eds.), Selling forest for environmental services: Marketbased mechanism for conservation and development (pp. 1-13). London: Earthscan.

PNPM Mandiri. (2009) What Is PNPM Mandiri? PNPM Mandiri Newsletter (II ed.). Jakarta: PNPM Mandiri Communication Team.

Instruksi Presiden Nomor 3 Tahun 2008 Tentang Pelaksanaan Program Bantuan Langsung Tunai untuk Rumah Tangga Sasaran, Nomor 3 Tahun 2008 C.F.R.

The International Rubber Research \& Development Board. (2012, December). Risks \& opportunities for the natural rubber industry 
within a low carbon economy. Presentasi pada International Workshop on Carbon Markets 2012, Bogor, 3-4 Desember 2012.

Yayasan Cakrawala Indonesia. (2013). Assessment report for socio-economic, climate change and environmental services forest at Buntoi Village, Central Kalimantan. Palangkaraya: Yayasan Cakrawala Indonesia. 